\title{
O LATIM E O PORTUGUÊS DAS PARTES DA ORAÇÃO ÀS CLASSES GRAMATICAIS
}

Luiz Roberto Peel Furtado de Oliveira é professor da Universidade Federal do Tocantins e Doutor em Letras Clássicas pela USP.

E-mail: 1uizpeel@uft.edu.br

\section{Resumo}

A prática dos estudos clássicos aprimora a análise lógica e a percepção estética; desenvolvendo, ainda, a percepção da necessária e profícua conjunção dos estudos da ciência com os estudos das humanidades e das artes; proporcionando, ainda, a compreensão lógica do fato linguístico pancrônico; e desenvolvendo a capacidade de análise, síntese, interpretação e avaliação crítica. Este trabalho apresenta, como princípios para atingir esses objetivos, os seguintes pontos: o conhecimento do fato linguístico latino por meio de textos, isto é, de dentro para fora (do concreto para o abstrato), sendo que os textos utilizados são aqueles das primeiras gramáticas latinas; a compreensão do fato linguístico como um fenômeno pancrônico; a aplicação do conhecimento adquirido em traduções de textos simples latinos e na interpretação do fato linguístico português; a inferência dos fatos linguísticos em categorias pragmático-lógicas; e a articulação de teoria e prática através de ações educativas capazes de instrumentalizar o aluno para a metodologia de incorporação dos saberes da área de Letras.

\begin{abstract}
The practice of classical studies enhances the logical analysis and the aesthetic perception; developing the necessary perception and profitable union of science studies and the studies of humanities and arts; providing the logical comprehension of the panchronic linguistic fact; and developing the analysis, synthesis and interpretation capacity and critical evaluation. This work presents, as the basis to achieve its goals, the following aspects: the knowledge of the Latin linguistic fact by using texts, that is, from the inside to the outside (from the concrete to the abstract), and the texts that were used are from the first Latin grammars; the comprehension of the linguistic fact as a panchronic phenomenon; applying the acquired knowledge in translations of simple Latin texts and in interpretation of the Portuguese linguistic fact; the inference of the linguistic facts in pragmatic and logical categories; the articulation between theory and practice through the educational actions that are able to empower the student in order to gather knowledge in the area of Languages.
\end{abstract}

\section{Introdução}

Este texto traduz, de modo simples e conciso, a experiência desenvolvida com alunos do Curso de Letras da Universidade Federal do Tocantins, no período circunscrito entre fevereiro de 2010 e julho de 2012. E convém destacar que a preocupação que norteou e inspirou o desenvolvimento desta proposta está fundamentada não só na apreensão da necessidade do trabalho com a língua latina para melhor compreensão dos fenômenos linguísticos do português, mas também na possibilidade de envolvimento real e proveitoso dos discentes com o trabalho de tradução e de compreensão do fato linguístico latino.

A proposta foi desenvolvida com cinco turmas, três do primeiro semestre de Língua Latina I e duas de Língua Latina II. E o que levou à sua criação foi o pouco interesse demonstrado pelos alunos durante o primeiro desses semestres. Com o desenvolvimento dos trabalhos, a partir desta proposta, os alunos passaram a se 
interessar mais, pois foi criada uma meta - a compreensão da divisão das palavras em classes ou categorias e o porquê dessas categorias.

Como referencial teórico, a partir de Bakhtin, considerando sempre a atividade dialógica como ponto de partida profícuo para o aprendizado, caminhamos para a Fenomenologia, que objetiva a recepção e compreensão do texto enquanto fenômeno significativo. Procuramos, dessa forma, estabelecer um diálogo constante com os primeiros gramáticos latinos, não se esquecendo do seu substrato grego, para que o fato linguístico português fosse contemplado dialogicamente em sua totalidade pancrônica.

Para salientarmos a necessidade dessa totalidade pancrônica, consideremos algumas linhas de Merleau-Ponty, que, em sua fenomenologia, trabalha com as noções de fundo e de intersubjetividade; leiamos, pois, um excerto de sua obra:

\begin{abstract}
Cada existência só transcende definitivamente as outras quando permanece ociosa e assentada em sua diferença natural. Mesmo a meditação universal que corta o filósofo de sua nação, de suas amizades, de seus preconceitos, de seu ser empírico, em uma palavra, do mundo, e que parece deixá-lo absolutamente só, na realidade é ato, fala por conseguinte diálogo. O solipsismo só seria rigorosamente verdadeiro para alguém que conseguisse constatar tacitamente a sua existência sem ser nada e sem fazer nada, o que é impossível, já que existir é ser no mundo. Em seu retiro reflexivo, o filósofo não pode deixar de arrastar os outros porque, na obscuridade do mundo, ele aprendeu para sempre a tratá-los como consortes, e porque toda a sua ciência está construída sobre esse dado de opinião. A subjetividade transcendental é uma subjetividade revelada, saber para si mesma e para outrem, e a esse título ela é uma intersubjetividade. (Merleau-Ponty, 1999, p. 484-485)
\end{abstract}

Nosso trabalho se baseou sempre num estudo comparativo entre os tratados gramaticais latinos, seguido de traduções para o português, feitas pelos próprios alunos, e de novas analogias com a teoria gramatical contemporânea no tocante às classes de palavras; tentando sempre a percepção do fundo no qual e do qual brotavam as deiscências (aberturas intelectuais ou cognitivas - sem as quais as teorias não se metamorfoseariam em novas posições ou aberturas teóricas), sem as quais, ainda, o fato nunca seria percebido e compreendido como fenômeno linguístico pancrônico; e almejando, em todo esse processo, a percepção da intersubjetividade como fenômeno dialógico primordial.

E é essa uma de nossas teses, sem a presença do outro, não surge a condição necessária para qualquer cognição; sem a presença do outro, não aparecem nem ocorrem as condições favoráveis para a deiscência do fenômeno linguístico, tanto sincronicamente quanto diacronicamente. E nossa insistência nesse vocábulo deiscência, justifica-se por nosso substrato fenomenológico, sem o qual o "dois" nunca será vivenciado tendo como fundo o "um", e as formas nunca serão compreendidas em seus cotextos e contextos (a pancronia se justifica fenomenologicamente).

E a deiscência ocorre quando vivenciamos cognitivamente a alteridade; seja sincronicamente, enquanto oposição de elementos do sistema (fundo contemporâneo);

Revista Escrita

Rua Marquês de São Vicente, 225 Gávea/RJ CEP 22453-900 Brasil

Ano 2012. Número 15. ISSN 1679-6888.

escrita@puc-rio.br 
seja diacronicamente, enquanto oposição de transformações do mesmo ser ou fenômeno linguístico (fundo histórico).

E é só essa consciência da presença concreta e evidente do outro que poderá permitir a abertura cognitiva. Outro pequeno excerto, desta vez de Sartre, nos ajudará a compreender esse fato:

Assim, pelo olhar, experimento o outro concretamente como sujeito livre e consciente que faz com que haja um mundo temporalizando-se rumo às suas próprias possibilidades. E a presença sem intermediários desse sujeito é a condição necessária de qualquer pensamento que tento formar a meu respeito. (Sartre, 1997, p. 348)

É necessário considerar o outro, e, no caso da língua portuguesa, o outro é também a língua latina; e os outros serão, evidentemente, todos os autores que trabalharam nessas primeiras gramáticas; sendo assim, a consideração do latim é importante para a percepção deiscente do fato linguístico do português enquanto fenômeno oriundo de deiscências; o que é, deveras, instigante para o professor de língua materna.

\section{1) As primeiras gramáticas}

A melhor introdução para nossa proposta de trabalhos com o latim foi, em função dos pressupostos teóricos que nortearam a criação dos compêndios gramaticais latinos, uma apresentação da obra de Dionísio Trácio (170-90 a.C.) - principalmente de seu parágrafo inicial - fonte de toda teoria gramatical da antiguidade; não só grega, mas também latina, e, para muitos, a primeira gramática do Ocidente. Ora, o leitor sabe da importância dos tratados linguístico-filosóficos gregos para o surgimento das teorizações latinas e, posteriormente, das portuguesas. Logo, partindo da primeira gramática, estabelecemos desde o início dos trabalhos o dialogismo como um dos princípios fundamentais.

Na sequência, explicamos para os alunos como a gramática era concebida para os primeiros tratadistas - conhecimento não teorizado, provindo apenas de experiências de análise textual ou filológica. Destacamos, também, que Dionísio fixou normas a partir do uso atestado nos textos de sua época, com a finalidade de preservar a cultura de seu povo, não considerando as antecipações lógicas propostas por Aristóteles acerca do enunciado linguístico e apresentando apenas preocupações com o nível estóico do significante; para, a partir das observações desses filósofos, criar um pequeno tratado, cujos traços fundamentais, ainda hoje, estão presentes na maioria das gramáticas ocidentais.

Destacamos, ainda, o parágrafo a respeito da palavra léxis:

Em relação à sintaxe, a palavra é a menor parte da oração. A oração é uma composição em prosa que manifesta um pensamento completo. São oito as partes da oração: nome, Revista Escrita

Rua Marquês de São Vicente, 225 Gávea/RJ CEP 22453-900 Brasil

Ano 2012. Número 15. ISSN 1679-6888.

escrita@puc-rio.br 
verbo, particípio, artigo, pronome, preposição, advérbio e conjunção. (Oliveira, 2011, p. 20)

Salientamos, também, a definição de oração (lógos), para comparação posterior com os tratados latinos: a oração, para todos esses gramáticos, era definida como uma composição que manifestava um pensamento completo; dessa forma, deixando de lado as diferenciações feitas por Aristóteles quanto aos vários tipos de oração, Dionísio generalizou, determinando-a como composição de oito partes possíveis; número apontado, a partir dele, como determinante da oração perfeita.

Um último dado explicitado da gramática grega foi a apresentação da noção de nome; Dionísio afirmou que é a parte com caso que significa um corpo ou ação:

O nome é uma parte da oração com caso, que significa um corpo ou uma ação; um corpo, por exemplo, pedra; uma ação, por exemplo, educação; afirmado de forma comum ou particular; comum, por exemplo, homem, cavalo; particular, por exemplo, Sócrates. O nome tem cinco acidentes: gênero, espécie, figura, número e caso. (Oliveira, 2011, p.20)

Esses cinco acidentes citados foram amplamente desenvolvidos - gêneros: masculino, feminino e neutro; espécies: primitiva e derivada (patronímica, possessiva, comparativa, superlativa, hipocorística, parônima e verbal); figuras: simples, composta e parassintética; números: singular, dual e plural; casos: direto, genitivo, dativo, causativo e vocativo.

Os alunos compreenderam, então, que o trabalho de Dionísio apresentava somente sistemas classificatórios, não considerando o significado nem a sintaxe; e que preocupações objetivas com o arranjo só aparecerão no segundo século depois de Cristo, com Apolônio Díscolo, que, organizando sistematicamente toda a matéria linguística sobre uma base filosófica, afastou-se do exame do aspecto exterior, típico da gramática alexandrina.

A seguir, levávamos os alunos a conhecerem outros comentaristas e gramáticos, que apenas parafrasearam ou copiaram Dionísio. Como exemplo dessas paráfrases, citemos o Comentário Bizantino - IX século d.C.:

O nome é parte declinável da oração. É considerado parte da oração, porque é uma das suas oito partes; é considerado declinável, porque admite casos; significando corpo ou ação; um corpo, como pedra; uma ação, como educação. Saiba que, segundo os gramáticos, corpo é tudo o que pode ser dominado pelo tato, e ação, o que não pode ser dominado pelo tato, mas pelo pensamento. (Keil, 1866, 12, p. 14-18)

De cópia, Constantino Lascaris - século XV:

A palavra é a menor parte divisível da oração composta. A oração é a composição composta de palavras que manifesta um pensamento completo. As partes dessa são oito: nome, verbo, particípio, artigo, pronome, preposição, advérbio e conjunção. Dessas,

\footnotetext{
Revista Escrita

Rua Marquês de São Vicente, 225 Gávea/RJ CEP 22453-900 Brasil

Ano 2012. Número 15. ISSN 1679-6888.

escrita@puc-rio.br
} 
cinco são declináveis: nome, verbo, particípio, artigo e pronome. E três são indeclináveis: preposição, advérbio e conjunção. O nome é parte declinável da oração, que significa essência particular ou comum. Apresenta cinco acidentes: gênero, espécie, figura, número e caso. (Lascaris, 1966, s.p.)

Constantino praticamente copia o trabalho de Dionísio, o que foi feito também pelos gramáticos posteriores, um copiando o outro, tanto na teoria quanto nos exemplos.

\section{2) As gramáticas latinas}

Após essa consideração dos tratados gregos, chegamos aos romanos, que encontraram na maioria das disciplinas acadêmicas a base do conhecimento já desenvolvida pelos gregos; tiveram, assim, duas alternativas em relação aos estudos linguísticos: a aplicação pura e simples, sem a menor alteração, do arcabouço classificatório e descritivo da gramática grega, ou o reexame dos sistemas gregos à luz dos fatos encontrados no latim. A maioria dos gramáticos latinos optou pela primeira alternativa.

Os alunos passaram a conhecer os tratadistas latinos, sempre lendo o texto original e fazendo traduções das partes relacionadas ao que tinham visto nas gramáticas gregas; e o conteúdo do que foi visto está relatado nos próximos parágrafos, que foi transcrito de modo sucinto, mas que, durante o trabalho, foi trabalhado e retrabalhado durante alguns meses.

Dentre os autores latinos, Varrão é o que exibe uma considerável reformulação dos termos e conceitos da gramática. Tendo percebido que, a par das semelhanças estruturais, algumas modificações precisavam ser feitas para uma aplicação coerente do descritivismo grego, Varrão estabeleceu três divisões para o estudo da língua: etimologia, morfologia e sintaxe (De L. L. VIII, I, apud Robins, 1951).

Infelizmente, seu estudo das relações das palavras nas sentenças e sua sintaxe se perderam; talvez tenham influenciado Apolônio Díscolo, o primeiro, pelo menos até onde conhecemos, que apresentou uma sintaxe elaborada no Ocidente.

Na morfologia, faz a distribuição das palavras na língua latina usando princípios puramente formais; sua primeira divisão é entre palavras variáveis e invariáveis. Quanto às partes da oração, usando métodos e termos inventados pelos gregos, elabora uma divisão própria, estabelecendo quatro classes de palavras: a primeira é aquela que possui casos - a dos nomes; a segunda, tempos - a dos verbos; a terceira possui os dois, casos e tempos - a dos particípios; e a quarta, que não possui nem um nem outro - a das partículas (Robins, 1951). Quando subdivide, depois, a classe nominal em quatro subclasses (pronomes interrogativos, nomes comuns, nomes próprios e pronomes demonstrativos), usa também outros critérios, que não formais (Ibidem). Quanto aos

Revista Escrita

Rua Marquês de São Vicente, 225 Gávea/RJ CEP 22453-900 Brasil

Ano 2012. Número 15. ISSN 1679-6888.

escrita@puc-rio.br 
verbos, revela a influência dos estóicos, pois também os chama de completos e incompletos (Ibidem).

Os outros gramáticos latinos, como já dissemos, copiaram a classificação grega; quando havia diferenças, faziam malabarismos para mantê-la. Foi assim que conservaram as oito partes da oração; não tendo artigos, substituíram-nos pelas interjeições. O primeiro tratadista que apresenta essas oito partes latinas é Remmius Palaemon, que viveu no primeiro século da nossa era, no tempo do imperador Claudius.

No mesmo século, um dos prováveis alunos de Palaemon, Quintiliano, em seu tratado de oratória, no capítulo dedicado à gramática, além de questionar a determinação do número de casos (Quintilianus, 1975), aponta, por meio de um pequeno histórico, o número e a natureza das partes da oração que deveriam ser ensinadas a todas as crianças:

Em seguida, examinará quantas e quais são as partes da oração, relacionando-as com os seus criadores, ainda que, quanto ao número, haja pouco acordo. Os antigos, de fato, dentre os quais Aristóteles e também Theodectes, apenas se referiram ao verbo, ao nome e às conjunções, certamente porque nos verbos encontramos o processo, nos nomes, a substância, e ainda porque um é o que é afirmado, o outro, a partir do que algo é afirmado; a respeito das conjunções, por outro lado, indicaram que são a conexão desses; as quais, eu sei, são chamadas de conjunções pela maioria dos estudiosos, o que parece ser a tradução mais apropriada de "sýndesmos". Paulatinamente, pelos filósofos e sobretudo pelos estóicos, o número foi aumentado; primeiramente, às conjunções são acrescentados os artigos, depois as preposições, aos nomes, a denominação, depois os pronomes; aos verbos, o particípio; mais tarde, aos próprios verbos, os advérbios. A nossa língua não precisa dos artigos e, por isso, estão espalhados nas outras partes da oração; entretanto, acrescenta a interjeição às partes mencionadas. (Quintilianus, 1975, I, p. 4)

Referindo-se a Aristóteles, Quintiliano não cita o termo hypokeímenon (conceito empregado pelo filósofo grego para indicar o sujeito do discurso, tanto filosófico quanto linguístico), pois, tratando-se de uma obra de oratória, sua abordagem dos conceitos e termos é apenas acidental. Porém, indiretamente, descreve-o com propriedade, quando afirma ser aquilo "a partir do qual algo é afirmado".

Do século seguinte, temos a gramática de Emílio Asper, uma adaptação reduzida da gramática de Dionísio Trácio:

Das partes da oração

As partes da oração são oito: nome, pronome, verbo, advérbio, particípio, conjunção, preposição e interjeição.

Do nome

O nome é a parte da oração pela qual cada coisa é chamada, quer seja animada, como homem, Catão; quer inanimada, como árvore, pedra; quer ainda incorpórea, como perfídia, clemência. Os nomes têm cinco acidentes: qualidade, gênero, número, figura e caso.

Do verbo

Revista Escrita

Rua Marquês de São Vicente, 225 Gávea/RJ CEP 22453-900 Brasil

Ano 2012. Número 15. ISSN 1679-6888.

escrita@puc-rio.br 
O verbo é a parte da oração com tempo e pessoa que significa a ação ou a passividade. São acidentes do verbo a qualidade, a significação, o número, a figura, o tempo, a pessoa e a conjugação. (Keil V, 1866, parte 2, p. 549-551)

Quanto às partes, temos a manutenção do número por meio da troca, já citada, do artigo pela interjeição. Quanto ao nome, a mesma desconsideração dos trabalhos de Aristóteles e de Apolônio, os quais, mesmo numa gramática simples e didática, deveriam estar presentes, ao menos nas entrelinhas. Asper mantém, ainda, os cinco acidentes, trocando apenas a espécie pela qualidade, com uma leve alteração semântica. Quanto ao verbo, encontramos a subtração de um acidente - a espécie, e com isso de oito passamos a sete.

Entretanto, somente no século seguinte ao de Asper, o terceiro, e sobretudo no quarto, no período tardio do império, é que acontece uma profusão de tratados gramaticais, dos quais os mais famosos são o de Donato (aproximadamente 400 d.C.) e o de Prisciano (aproximadamente 500 d.C.).

$\mathrm{Na}$ educação desse período, os estudos literários haviam suplantado os filosóficos, e essa mudança ocasionou alterações também nos métodos dos gramáticos. As escolas, que se multiplicavam, precisavam de compêndios didáticos, e assim foram feitas cópias, adaptações e, frequentemente, deformações tanto das obras literárias quanto dos tratados gramaticais. Essas adaptações e resumos tiveram, principalmente no domínio da terminologia, um resultado irracional: os gramáticos, não sendo mais capazes de justificar os conceitos que usavam, caíam na incoerência. Quando citarmos a obra de Sérgio, exemplificaremos tal ilogismo.

Nos tratados de Donato e Prisciano, não há inovação; o primeiro traduz praticamente Dionísio, enquanto que o outro comenta os trabalhos de Apolônio. A única idéia original do período foi concebida por Macróbio (aproximadamente 400 d.C.), que escreveu um estudo comparativo dos sistemas verbais latino e grego (Keil, 1866, volume V).

A obra de Donato apresenta duas versões, a primeira somente recria Dionísio, enquanto que a segunda acrescenta algumas afirmações de Quintiliano. Citemos a mais completa:

Das partes da oração

As partes da oração são oito: nome, pronome, verbo, advérbio, particípio, conjunção, preposição e interjeição. Dessas, duas são as principais partes da oração: nome e verbo. Os latinos não incluem o artigo; os gregos, a interjeição. Muitos consideram as partes da oração em maior número; muitos em menor. Realmente, de todas, apenas três são as que em seis casos são flexionadas: nome, pronome e particípio. (Holtz, 1981, p. 613)

Via oratória (Quintiliano), a importância maior do nome e do verbo está contida em Donato, mas é só isso; não há preocupações com a sintaxe. Nada é dito em relação ao sujeito, como provam os textos a respeito do nome e do verbo citados abaixo:

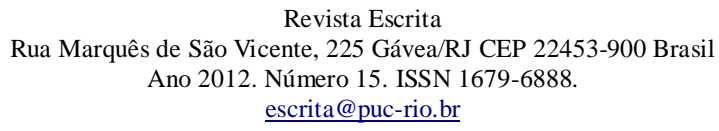


Do Nome

O nome é a parte da oração com caso que significa corpo ou ação, de modo próprio ou comum. Próprio, como Roma e Tibre; comum, como cidade e rio. O nome tem seis acidentes: qualidade, comparação, gênero, número, figura e caso. Há o nome de um homem, a denominação de muitos e o nome próprio das ações. Mas, de modo geral, dizemos apenas nomes.

Do verbo

O verbo é a parte da oração com tempo e pessoa, sem caso, que significa ou o ativo ou o passivo ou o neutro. O verbo tem sete acidentes: qualidade, conjugação, gênero, número, figura, tempo e pessoa. (Holtz, 1981, p. 614-632)

O que encontramos, então, é praticamente o tratado de Dionísio Trácio. Novamente, todas as antecipações aristotélicas são deixadas de lado, em prol de um didatismo baseado apenas em um descritivismo classificatório. Novamente, ainda, como entre os gregos, em relação a Dionísio, aparecem inúmeros comentários da gramática de Donato, todos problemáticos e confusos: Carísio, Diomedes, Sérgio, Consêncio e Sérvio (todos coevos de Donato).

Destaquemos alguns deles.

Em Carísio temos quase uma cópia de Donato. No tocante à oração e seus componentes, encontramos, de diferente, apenas uma definição:

Da oração

A oração é emitida pela voz e, por meio das dicções, uma declaração ordenada, como expressão do pensamento. (Keil, 1866, p. 193)

Em Diomedes encontramos a fonte grega da oris ratio:

Da oração

A oração é um arranjo ordenado de palavras voltado para uma conclusão delimitada. Alguns assim a definem: a oração é uma composição de dicções consumando um pensamento e significando, ainda, uma realidade completa. Assim Carros: a oração é emitida pela voz e, por meio das dicções, uma declaração ordenada. Por outro lado, a oração parece ser ensinada como expressão do pensamento, ou, como no grego, "ao tudo oarídzein", isto é, conversar. Donde Homero, “oarídzeton alléloisin”. A oração é conversa entrelaçada, tendendo a um fim. (Keil, 1866, p. 300)

Quanto ao que é dito a respeito das partes da oração, ambos, Diomedes e Carísio, apresentam as mesmas definições e os mesmos exemplos de Donato, não acrescentando, como aquele também não havia feito, nenhuma referência ao sujeito.

\section{3) O retorno medieval à abordagem semântica}

A seguir, caminhamos pelos lógicos medievais, sempre continuando em nossa trajetória dialógica.

Revista Escrita

Rua Marquês de São Vicente, 225 Gávea/RJ CEP 22453-900 Brasil

Ano 2012. Número 15. ISSN 1679-6888.

escrita@puc-rio.br 
Com os Modistae, pensadores medievais que objetivaram a gramática como filosófica, encontramos a formação modal das classes de palavras como encontramos hodiernamente. $\mathrm{E}$ as partes da oração passaram a ser distinguidas por meio dos modos ativos de significação, ou seja, por meio da maneira pela qual significam as qualidades ou propriedades das coisas. Houve uma retomada da obra de Aristóteles, sobretudo de sua epistemologia; entretanto, em relação ao conteúdo das gramáticas, houve pouca mudança, uma vez que a insistência da repetição do modelo gramatical grego, via Prisciano, persistiu.

Um dos grandes autores desse grupo foi Thomas de Erfurt, que apresentou um tratado gramatical completo no mesmo estilo dos Modistae, que se tornou o mais conhecido tratado filosófico medieval sobre a linguagem. Nele, Thomas nos dá uma interpretação filosófica da divisão das partes da oração encontrada em Prisciano. Vejamos a sua definição de nome: "O nome é a parte da oração que significa por meio do modo de ser" (Erfurt apud Buescu, 1983, 157). Tal definição, citada por Buescu, foi retirada do capítulo VIII da Grammatica Speculativa de Thomas de Erfurt. Erfurt diferenciou, ainda, o nome substantivo do nome adjetivo: "O modo de significar por meio de um modo por si subsistente [...] constitui o nome substantivo. Nome adjetivo significa por meio de um modo de algo inerente a outro" (Ibidem).

Como os lógicos medievais também trabalharam em latim, foi um exercício também profícuo a leitura e tradução de alguns excertos de suas obras.

Contemplemos parte de um dos textos lidos por nossos alunos (Wallerand. Les Oeuvres de Siger de Courtrai - Les Philosophes Belges, Tome VIII, p. 94-95):

Voz... é voz a partir de uma ação de proferir... formalmente, é chamada de parte da oração por meio de um modo ativo de significação; entretanto, os modos ativos de significação não estão na voz, assim como no sujeito, pois os modos ativos de significação são um certo conceito próprio do intelecto; assim sendo, os conceitos do intelecto permanecem no intelecto e não passam para fora; todavia, são denominados vozes e por meio delas, por sua vez, são construídos, do mesmo modo que o universal existente no intelecto denomina a coisa exterior. (Robins, 1951, p. 94)

Retomemos: por meio da linguagem, a mente outorga a sons vocais os modos ativos de significação (modi significandi activi), em virtude dos quais esses sons tornam-se dicções e partes da oração, significando, ainda, as qualidades das coisas, que são representadas por meio de modos passivos de significação (modi significandi passivi).

Robins apresenta o seguinte esquema para a concepção da linguagem dos Modistae:

Nível do ser - MODI ESSENDI

Nível da compreensão - MODI INTELLIGENDI ACTIVI e PASSIVI

Nível da expressão - MODI SIGNIFICANDI ACTIVI e PASSIVI (Ibidem, p. 83)

\footnotetext{
Rua Marquês de São Vicente, 225 Gávea/RJ CEP 22453-900 Brasil

Ano 2012. Número 15. ISSN 1679-6888.

escrita@puc-rio.br
} 
Consequentemente, as partes da oração somente podem ser distinguidas por meio dos modos ativos de significação, ou seja, por meio da maneira pela qual significam as qualidades ou propriedades das coisas. Houve uma retomada, como já dissemos no início deste capítulo, da obra de Aristóteles, sobretudo de sua epistemologia; entretanto, em relação ao conteúdo das gramáticas, houve pouca mudança, uma vez que a insistência da repetição do modelo gramatical grego, via Prisciano, persistiu.

Entretanto, esses esforços na busca de precisas definições não alcançaram, de maneira prática, os tratados gramaticais; pois, nessas obras, em relação ao conceito de sujeito, nada é acrescentado ao que Prisciano havia dito. Vejamos alguns trechos da gramática de Roger Bacon (século XIII); poucos, pois também são poucas as diferenças em relação ao autor latino: "A gramática é, conforme a substância, una e a mesma em todas as línguas, ainda que, acidentalmente, haja variações" (Roger Bacon, 1902, p. 278).

Apesar de ter afirmado a unidade da gramática em todas as línguas, não buscou essa unidade em seu tratado, preferindo insistir nos modelos tradicionais, alterando apenas a ordem da apresentação da matéria:

Passando à antonímia [sic], a qual chamamos de pronome, e não seguindo, em relação a ele, a ordem grega ou a de Prisciano, visto que não intento discorrer acerca da invenção dos pronomes, os quais foram inventados depois dos verbos, para que suprissem a ausência do nome na primeira e na segunda pessoa dos verbos; visto que, verdadeiramente, foram inventados para o lugar do nome, e desde que significam a substância do nome, embora difiram no modo de significação, pois os nomes significam, como se diz, a substância com qualidade, e os pronomes, sem qualidade, e, ainda, porque no lugar do nome são compreendidos e principalmente no lugar dos nomes próprios, pois é próprio do pronome ser colocado no lugar do nome próprio [...]. E, sobretudo, quando a oração perfeita, que é considerada pelo gramático, pode suficientemente ser feita de nome ou pronome e verbo; o verbo é o fim de tal oração e o complemento, o nome e o pronome, por outro lado, são o princípio. (Ibidem, p. 158165)

Temos aqui, evidentemente, a retomada da ordem lógica de Aristóteles e Apolônio. O nome é definido como o princípio da oração, e o predicado, como fim, como a sequência de coisas que, a partir do sujeito, são afirmadas.

Reiteremos: baseando o estabelecimento das partes da oração e as suas categorias secundárias em distinções lógicas e metafísicas, Roger Bacon, na concepção prática da gramática, continuou estritamente ligado ao sistema classificatório de Prisciano e Donato, pois não apresentou uma sintaxe substancial, na qual poderia ter elaborado de maneira criativa as antecipações aristotélicas, que foram somente em parte desenvolvidas pelos teóricos da época, já que tiveram o entrave do modelo gramatical clássico.

Os alunos fizeram um percurso dialógico, lendo e traduzindo textos que foram sendo construídos por meio de igual dialogismo.

Revista Escrita

Rua Marquês de São Vicente, 225 Gávea/RJ CEP 22453-900 Brasil

Ano 2012. Número 15. ISSN 1679-6888.

escrita@puc-rio.br 


\section{Conclusão: das partes da oração às classes gramaticais}

Assim, pouco a pouco, as partes da oração foram se constituindo em classes; e das oito partes de Dionísio chegamos às classes da gramática normativa atual. Recordemos o excerto da "primeira gramática": "São oito as partes da oração: nome, verbo, particípio, artigo, pronome, preposição, advérbio e conjunção". O nome, com os Modistae, foi dividido ou, pela deiscência, foi compreendido como substantivo e adjetivo; o particípio retornou ao verbo. E a interjeição, colocada pelos romanos no lugar do artigo, para o alcance da frase perfeita de oito partes, passou, da mesma forma, para a língua portuguesa.

Nosso percurso com os alunos foi sendo trabalhado com traduções e interpretações dos primeiros tratados gramaticais, o que possibilitou uma visão pancrônica e fenomenológica do fato linguístico; que, por sua vez, provocou deiscências profícuas em relação à língua portuguesa.

\section{Referências Bibliográficas}

ALBUQUERQUE, Irene T. de. "A evolução do conceito de gramática dos gregos aos ingleses do século XVII". In Miscelânea de Estudos. Lisboa: Comissão Científica do Departamento de Estudos Anglo-americanos da Faculdade de Letras de Lisboa, 1985.

ARNAULD et LANCELOT. Grammaire Générale et Raisonnée. Paris: Républications Paulet, 1969 (avec les remarques de Duclos et préface de Michel Foucault).

ARNAUlD, Antoine. Gramática de Port-Royal/Arnauld e Lancelot. São Paulo: Martins Fontes, 1992.

BACON, Roger. The Greek grammar. Cambridge: The University Press, 1902.

BRUN, Jean. Les Stoïciens. Paris: Presses Universitaires de France, 1962.

DAHLMANN, Hellfried. Zur Ars Grammatica des Marius Victorinus. Mainz: Verlag der Akademie der Wissenschaften un der Literatur, 1970.

EGGER, E. Apollonius Dyscole - Essai sur l'histoire de théories grammaticales. Paris: Auguste Durand Librairie, 1854.

EMMANUELIS ALVARI. Institutio Grammatica. Roma: Horatio Tursellini S.J., 1832.

\footnotetext{
Revista Escrita

Rua Marquês de São Vicente, 225 Gávea/RJ CEP 22453-900 Brasil

Ano 2012. Número 15. ISSN 1679-6888.

escrita@puc-rio.br
} 
FORCELLINI, Aegidio. Lexicon Totius Latinitatis. Patavii Typis Seminarii, MCMXXXX, tom. IV.

HAUY, Amini B. Da Necessidade de uma Gramática-Padrão da Língua Portuguesa. São Paulo: Ática, 1987.

HILGARD, Alfredus. Theodosii Alexandrini - Georgii Choerobosci - Sophronii Patriarchae Alexandrini. Lipsiae: Aedibus B.G. Teubneri, 1894.

HOLTZ, Louis. Donat et la tradition de l'enseignement grammatical. Paris: C.N.R.S., 1981.

JESPERSEN, Otto. La Philosophie de la Grammaire. Paris: Les Éditions de Minuit, 1971.

KEIL, H. Grammatici Latini. Lipsiae: Aedibus B.G. Teubneri, 1866.

KÜHNERT, F. Flavii Sosipatri Charisii - Artis Grammaticae. Lipsiae: Aedibus B.G. Teubneri, 1964.

LALLOT, Jean. La Grammaire de Denys le Thrace. Paris: C.N.R.S., 1989.

LASCARIS, Constantinus. Greek Grammar. Amsterdam: Adolf M. Hakkert-Publisher, 1966.

LENTZ, Augustus. Herodiani Technici - Reliquiae. Lipsiae: Aedibus B.G. Teubneri, 1870 , tomi II, fasciculus posterior.

MARIOTTI, Italo. Marii Victorini - Ars Grammatica. Firenze: Felice le Monnier, 1967.

MERLEAU-PONTY, Maurice. Fenomenologia da percepção. São Paulo: Martins Fontes, 1999.

MEYER-LÜBKE, W. Grammaire des Langues Romanes. Vienne: G. E. Stechert \& Co., 1923.

MOUNIN, Georges. Historia de la Lingüística. Madrid: Gredos, 1971.

MURACHCO, Henrique. Língua Grega - visão semântica, lógica, orgânica e funcional. Petrópolis, RJ: Vozes, 2001.

OLIVEIRA, Fernão de. A Gramática da Linguagem Portuguesa. Lisboa: Imprensa Nacional - Casa da Moeda, 1975.

OLIVEIRA, Luiz Roberto Peel Furtado de. A Gramática de Dionísio Trácio e seus contrapontos semânticos. Campo Grande: Editora Oeste, 2011.

$$
\begin{gathered}
\text { Revista Escrita } \\
\text { Rua Marquês de São Vicente, 225 Gávea/RJ CEP 22453-900 Brasil } \\
\text { Ano 2012. Número 15. ISSN 1679-6888. } \\
\text { escrita@ puc-rio.br }
\end{gathered}
$$


PROTÁGORAS. Fragmentos y Testimonios. Buenos Aires: Aguilar, 1965.

QUINTILIANUS, M. Fabius. Instituto Oratoriae. Paris: Les Belles Lettres, 1975.

ROBINS, R. H. Ancient \& Mediaeval Grammatical Theory in Europe. London: G. Bell \& Sons Ltd., 1951.

STEPHANUS, Henricus. Thesaurus Graecae Linguae. Parisiis: Instituti Franciae Typ., 1865.

UHLIG, Gustavus. Dionysii Thracis Ars Grammatica. Lipsiae: in Aedibus B. G. Teubneri, 1883.

Apollonii Dyscoli Quae Supersunt. Lipsiae: in Aedibus B. G. Teubneri, 1910. 